\title{
Análisis narrativo y creación de series dramáticas: la primera temporada de la serie Los $\mathbf{8 0}$
}

Narrative analysis and creation of drama series: The first season of the television series Los 80

\section{Pablo Unda}

Universidad Carlos III de Madrid, Madrid, España

pabloundaagmail.com

\section{Paz Crisóstomo}

Universidad Carlos III de Madrid, Madrid, España

paz.crisostomodalumnos.uc3m.es

\section{Resumen}

Los 80 (2008-2014) una de las series de ficción chilenas más destacadas en términos de críticas y resultados de audiencia, motiva un análisis narrativo enfocado en el primer capítulo de esta producción, para profundizar en el estudio dramático de series televisivas que logran una fuerte identificación y anclaje entre los espectadores a lo largo de varias temporadas. Se desarrolla una Matriz de Construcción de Series, que busca contribuir al análisis y creación de ficciones seriadas que aspiran a un público amplio dispuesto a mirar, y volver a mirar, una historia compuesta por varios capítulos. Se establece finalmente que esta relación es posible a través de un capítulo piloto que contempla recursos dramáticos que posibilitan una emocionante y coherente expansión narrativa de la serie.

Palabras clave: Ficción televisiva, dictadura, memoria, recepción.

\begin{abstract}
Los 80 (2008-2014), one of the most outstanding Chilean fiction series in terms of critics and audience results, motivates a narrative analysis focused on the first chapter of this show, to deepen in the dramatic study of serials stories that achieves a strong identification and anchorage in viewers over several seasons. This allows to develop a Series Construction Matrix, which seeks to contribute to the analysis and creation of fiction series that aspire to a wide audience willing to watch land watch over againl a story composed by many episodes. It is finally established that this relationship is possible through a pilot that includes dramatic features that make possible an exciting and coherent narrative expansion of the series.
\end{abstract}

Keywords: Television fiction, dictatorship, memory, reception. 


\section{Introducción}

Los 80 (2008-2014), serie del género drama centrada en una familia de clase media en el contexto de la dictadura que gobernó Chile entre 1973 y 1990, se extendió por 7 temporadas y 78 capítulos con destacados resultados de audiencia (Ver Tabla 1). El fuerte vínculo de la historia de Los Herrera con los espectadores se demostró una vez más desde diciembre de 2019 con la reprogramación de la serie en Canal 13. El reestreno ha alcanzado el segundo lugar de su franja con peaks de 10 puntos, incrementando en $16 \%$ el rating de la estación en ese horario (Fotech, 2020).

No existen series dramáticas chilenas que se acerquen a los registros de longevidad y audiencia de Los 80. La falta de anclaje de diversas producciones locales de este género entre los espectadores nacionales es una situación sobre la que se quiere dar luces tomando como punto de arranque un análisis narrativo detallado del primer episodio de Los 80 con el fin de, parafraseando a Ginzburg (1994), encontrar los indicios con los que esta serie marca diferencias. Siguiendo a autores como Goldberg y Rabkin (2003) y Balló y Pérez (2005), partimos de la base que la prolongación y el interés atemporal que logra una serie se fundamentan en la construcción dramática de su primer episodio. Bajo esta premisa, realizamos un estudio profundo del piloto o capítulo uno de $\operatorname{Los} 80$, obteniendo una Matriz de Construcción de Series (Ver Tabla 2) que se espera sirva de insumo a estudiantes y profesionales del rubro audiovisual para analizar y crear ficciones seriadas considerando parámetros artísticos y comerciales de la industria.

\section{Marco teórico}

Existen diversas publicaciones sobre Los 80 con objetivos distintos al nuestro en Castillo, Simelio y Ruiz (2010), Schlotterbeck (2014), Antezana (2015), Antezana y Mateos-Pérez (2017) y Mateos-Pérez y Ochoa (2018). Por un lado, comparan la serie con otras que recrean contextos dictatoriales, como la chilena Los Archivos del Cardenal (2011-2014) y las españolas Cuéntame cómo pasó (2001-) y Amar en Tiempos Revueltos (2005-2012). También analizan temas propios de la época que aborda la producción, como la crisis económica y diversos hitos político-sociales. Por ejemplo, la inserción de dueñas de casa en el mercado laboral.

En otro estudio, Mateos-Pérez y Ochoa (2016) analizan Los 80 desde la representación de género considerando otras dos producciones locales, la mencionada Los Archivos del Cardenal y El Reemplazante (2012-2014). Los autores concluyen que el espacio doméstico de los protagonistas determina relaciones de género estandarizadas que responden al modelo patriarcal y que el relato tiene un comienzo innovador que deviene en una representación simplificada. Otra conclusión de este trabajo es que, pese a que ciertos sectores cuestionan la falta de crítica política y/o el mensaje de consenso de la ficción, ésta logra la implicación del espectador en dos niveles: por la calidad de la historia y el vínculo que se produce con la memoria de la época.

Los estudios mencionados permiten "plantear otras posibilidades analíticas (...) examinando los resultados que se ha obtenido en otras aplicaciones" (Aumont \& Marie, 1990, pp. 268-269). Nos interesa, en específico, profundizar en los argumentos que se han expuesto para afirmar que la narración de Los 80 sobresale en términos cualitativos, siempre en función de nuestro fin práctico: estudiar en detalle el piloto de una serie que termina demostrando un fuerte vínculo con la audiencia tanto en su época de emisión como con posterioridad, sustentando así un modelo para analizar y crear series de ficción "atemporales".

Respecto a la creación de una serie, la industria audiovisual denomina biblia al documento donde su autor expone una guía del proyecto o formato (Douglas, 2011) o una descripción de su contenido (Toledano \& Verde, 2007). La extensión y estilo de la biblia depende de factores como el género de la serie y su receptor. Éste comprende canales de televisión, productoras audiovisuales, plataformas de distribución, entre otros. El objetivo principal de una biblia es transmitir los pilares de la serie en términos de cómo se puede narrar, producir, exhibir y comercializar. La construcción dramática de una serie, entonces, comienza a tomar forma en la biblia cuando el autor define las particularidades de su proyecto de acuerdo con conceptos como logline, storyline, género, personajes, argumento, tema(s), tono, tratamiento audiovisual, descrip- 
ción de locaciones y proyecciones narrativas. Más allá de entrar en detalles o discusiones sobre los distintos elementos que componen una biblia y la manera de plantearlos, lo esencial es cómo en la práctica se traducen en términos narrativos en el guion del primer capítulo, piedra angular sobre la que se sostiene finalmente la sobrevida de un formato seriado. En la industria es común afirmar que en el capítulo uno "se juega la serie", frase que va más allá del resultado de audiencia del primer episodio. Se refiere, también, a la capacidad de la producción para demostrar desde su origen que cuenta con suficientes recursos narrativos para extenderse atractivamente hasta su posible final. Como afirman Pérez \& Garín (2013):

Frente a las leyes inherentes al relato ${ }^{i-}$ neal, que no puede prescindir de un origen y un desenlace, los universos de ficción serial contienen la memoria de un Génesis y pueden aludir a un posible Apocalipsis, pero su interés -y la proliferación de su infinito devenir episódico- está en el durante (p.589).

Para sostener la emoción de una historia seriada desde su inicio hasta su eventual desenlace, el autor despliega en el piloto diversos recursos dramáticos a los que da nueva forma narrativa en cada capítulo siguiente. Según Goldberg y Rabkin (2003): "Cada serie tiene una contradicción central. Tiene que ser el mismo programa todas las semanas, pero al mismo tiempo, tiene que ser nuevo, fresco y diferente" (p.14). En cada nuevo capítulo el espectador establece relaciones entre lo conocido que se reconoce y lo desconocido que aporta novedad. Es decir, los conflictos, las situaciones y las dinámicas de personajes que se narran en el primer capítulo son renovados en cada nueva entrega de manera que, cual leitmotiv, cada capítulo relata siempre lo mismo, pero de manera diferente. De esta forma la narración seriada es deliberadamente reiterativa y novedosa a la vez, porque ese juego entre lo recursivo y lo inédito es necesario para obtener la complicidad y el compromiso emocional del espectador y, con eso, su interés a lo largo de varios capítulos.

Los conceptos de origen y desenlace, o de Génesis y Apocalipsis, nos remiten a las nociones de detonante y clímax de una historia. El detonante dramático, o incidente incitador en palabras de McKee (2002), es el suceso que desencadena el conflicto central de la historia y, a su vez, determina el momento cúlmine del relato, previo a su cierre. Antes y después de McKee, otros teóricos del relato audiovisual como Field (2001) plantean que, para desarrollar una historia, es necesario tener claridad de su detonante y su clímax. Considerando que estos autores se refieren a largometrajes o historias unitarias: ¿esta conclusión es válida para una historia seriada que se puede extender por bastantes más horas que las contempladas por su creador? Se puede afirmar que no hay una única respuesta debido a las particularidades de la industria de series. Rodrigo Cuevas, guionista de $\operatorname{Los} 80$, admite que con el equipo de producción trabajaron en la primera temporada pensando que sería la única (R. Cuevas, comunicación personal, octubre de 2009). Más allá de esta circunstancia, la primera temporada de Los 80 plantea una clara relación dramática entre su detonante (capítulo 01) y clímax (capítulo 10), lo que, como se verá, es clave para generar en el espectador un alto interés en el relato de la serie y, como consecuencia, su prolongación.

El punto de partida más adecuado para analizar la longevidad de una producción como Los 80 es estudiar en detalle el capítulo uno de acuerdo con su capacidad de serialidad, que Balló y Pérez (2005) definen como "una cadena infinita de sucesos intermedios" (p. 18). El autor de una serie busca plantear en el piloto un mundo dramático y un relato destinados a una amplia cantidad de capítulos, lo que hace necesario que el episodio permita vislumbrar varias nuevas entregas que por sí mismas y en conjunto consigan el interés del espectador.

\section{Marco metodológico}

Se estudia el capítulo uno de Los 80, "Un Penal a Colores", realizado por Wood Producciones y emitido por Canal 13 de Chile el 12 de octubre de 2008 en prime time, disponible en la página web de la cadena y la plataforma YouTube. Desde una metodología cualitativa de análisis del relato se examina cómo en este primer episodio se integran narrativamente el mundo dramático, los personajes, los conflictos y las proyecciones dramáticas de la serie. El objetivo general es ver cómo el capítulo uno determina el despliegue del relato en cada 
nuevo capítulo y el interés que la serie despierta en el tiempo. En relación con esto, los objetivos específicos son dos: 1) Identificar los recursos narrativos del primer capítulo de Los 80 y cómo se utilizan a lo largo del mismo episodio, y 2) Establecer cómo se reflejan en el capítulo uno de Los 80 las proyecciones dramáticas de la serie.

Para este segundo objetivo nos detenemos en el capítulo 10 de la producción, último de la primera temporada, en función de verificar cómo se expresan en el relato las proyecciones dramáticas que se fundan en el piloto. Para profundizar en los ob- jetivos generales y específicos de este trabajo en relación con las especificidades de la narración audiovisual seriada, se relacionan los conceptos expuestos hasta ahora (biblia, serialidad, continuismo novedoso, detonante y clímax), recurriendo a un corpus de autores que ha estudiado la narración audiovisual con énfasis en relato seriado (Balló \& Pérez, 2005; Cascajosa, 2007; Douglas, 2011; Field, 2001; Goldberg \& Rabkin, 2003; McKee, 2002; Pérez \& Garín, 2013; Toledano \& Verde, 2007), lo que permite el diseño de una Matriz de Construcción de Series.

Tabla 1: Promedio de audiencia por temporada Los 80

\begin{tabular}{c|c|c|c} 
Temporada & Episodios & Emisión & Audiencia promedio (rating) \\
\hline 1 & 10 & 12 de octubre de $2008-21$ de diciembre de 2008 & 20.9 \\
\hline 2 & 10 & 18 de octubre de $2009-27$ de diciembre de 2009 & 25.4 \\
\hline 3 & 10 & 17 de octubre de $2010-19$ de diciembre de 2010 & 29.8 \\
\hline 4 & 11 & 16 de octubre de $2011-20$ de diciembre de 2011 & 25.8 \\
\hline 5 & 12 & 23 de septiembre de $2012-16$ diciembre de 2012 & 23.1 \\
\hline 7 & 12 & 13 de octubre de $2013-12$ de enero de 2014 & 21,2
\end{tabular}

Fuente: Kantar Ibope Media

Tabla 2: Matriz de Construcción de Series; Capítulo Uno de Los 80

\section{MUNDO NARRATIVO}

Se establece en el comedor de una familia chilena de clase media, Los Herrera, que mira en un televisor blanco y negro al General Pinochet despidiendo a la Selección de Fútbol que disputará el Mundial de España 82.

PERSONAJES

Principales: La familia Herrera: Juan y Ana, y sus hijos Claudia, Martín y Félix.

Secundarios: Exequiel, Genaro, Petita y Bruno.

\section{CONFLICTO PRIMER ACTO}

Detonante trama uno (historia central): Juan, el protagonista de la serie, duda si tomar un crédito para comprar un televisor a color como regalo de aniversario para Ana.

Detonante trama dos: Claudia deja claro su desprecio por Pinochet.

Detonante trama tres: A Félix se le rompen sus zapatillas previo a la final de un campeonato de fútbol escolar.

Primer punto de giro: El inminente ascenso laboral de Juan.

\section{CONFLICTO SEGUNDO ACTO}

Desarrollo trama uno: Sin tener la certeza de si lo ascenderán en la fábrica, Juan compra un televisor a crédito y además zapatillas para Félix.

Desarrollo trama dos: Claudia enfrenta a Martin criticando a los militares chilenos, acrecentando la tensión entre ambos hermanos.

Desarrollo trama tres: Félix pierde un penal que patea con sus zapatillas nuevas y luego las rompe por accidente. Sus compañeros lo molestan y miente para no ir al colegio.

Segundo punto de giro: la dictadura devalúa el dólar y la empresa donde Juan trabaja entra en crisis económica. 
Clímax trama uno: Juan intenta calmar a su familia por la crisis de su empresa, pero termina alterándose y exigiendo no hablar de dinero (trama queda abierta).

Clímax trama dos: Claudia culpa a los militares de la crisis enfrentándose a Martín y a sus padres. Juan le reitera a su hija no hablar de política, pero ella persiste (trama queda abierta).

Clímax trama tres: Félix se desahoga con Juan confesándole que perdió el penal y rompió las zapatillas nuevas. Juan logra animarlo (cierre de trama).

\section{PROYECCIONES DRAMÁTICAS FUNDADAS EN EL PILOTO}

Juan: ¿Podrá sacar adelante a su familia si pierde su trabajo?

Ana: ¿Qué hará frente a la crisis laboral de Juan?

Claudia: Si insiste en meterse en política, ¿cómo afectará su relación con su familia, su pareja y sus aspiraciones de estudiar medicina? Martín: ¿Será aceptado en la Fuerza Aérea? ¿Se distanciará aún más de Claudia?

Félix: ¿Cómo lo afectará la crisis económica? ¿Cuál será su nueva aventura?

Exequiel: ¿Cómo lo perjudicará el inminente cierre de la fábrica y su postura política?

Genaro-Petita: ¿Los afectará realmente la crisis económica? (Rol de alivio cómico).

Bruno: ¿Será soporte de Félix en una nueva aventura?

Fuente: Elaboración propia.

\section{Resultados y Análisis}

El capítulo uno de Los 80 tiene 63 escenas. 19 contienen imágenes de archivo. De estas 19 escenas, 15 corresponden a imágenes que provienen de un televisor y gatillan conflictos y dinámicas entre personajes. Las cuatro restantes son en rigor secuencias o clips sobre el contexto histórico, funcionando como transiciones de tiempo.

El archivo audiovisual de la década es relevante desde los créditos iniciales para cimentar el mundo narrativo y el continuismo novedoso de la serie. La secuencia de apertura al ritmo de El Tiempo en Las Bastillas (1978) del cantautor chileno, Fernando Ubiergo, contiene diversas imágenes representativas de la época. Al inicio del coro se nos muestra por primera vez a Los Herrera, la familia protagónica, en formato de video casero, recurso también usado en el opening de series del mismo género como The Wonder Years (1988-1994) y Cuéntame cómo pasó (2001-). El entorno material que exhibe el registro, junto con las vestimentas y los looks de los miembros del núcleo familiar, delatan que los protagonistas son de clase media, representación que se refuerza cuando luego la secuencia de apertura nos presenta a los amigos y vecinos de Los Herrera.

El piloto abre con un televisor blanco y negro en el living-comedor de la familia. El viejo aparato co- mienza a emitir imágenes borrosas. Juan, el padre de familia, y su hijo mayor, Martín, interrumpen su cena para arreglarlo. Félix, el niño de la casa, advierte una noticia sobre la selección chilena de fútbol y urge a su padre para que arregle el televisor. "Puro golpe", comenta Juan mientras intenta arreglar el aparato a golpes de puño al tiempo que se vislumbra la imagen del General Pinochet. Ana le pide a su marido que tenga cuidado y no golpee la tele. Siguiendo la idea de transtextualidad de Genette (1989) "todo lo que pone el texto en relación, manifiesta o secreta, con otros textos" (pp. 9-10), el comentario y la acción de Juan de golpear el televisor mientras se distingue la imagen del militar que derrocó a Allende se puede tomar como una declaración de principios de la serie: en Chile hubo golpe de estado en 1973. La frase de Ana es quizá la primera antítesis de la tesis o punto de vista de la historia, encarnada en Juan, aspecto que se analiza más adelante y que puede sintetizarse en la pregunta: ¿es el televisor maltratado la metáfora de un país golpeado, con el (en el) que hay que tener cuidado?

La escena de apertura prosigue con Claudia, la hija mayor, logrando que el televisor por fin funcione. ¿Es ella, o personas como ella, los llamados a arreglar la televisión/el país? En definitiva la televisión golpeada es reflejo y metáfora de Chile, además de impulsor del relato. Tras la intervención de Claudia, la televisión ahora muestra en nítido blanco y 
negro a Pinochet en el Palacio de La Moneda despidiendo a los futbolistas que disputarán el Mundial de España 1982. El desprecio de Claudia es evidente ante la imagen del dictador. Por su lado Félix, siempre ajeno a lo político, se emociona al ver al futbolista Carlos Caszely, delantero estrella del equipo y reconocido opositor al régimen, que saluda tenso al militar. De este modo, en la primera escena se logra perfilar a los distintos miembros de la familia protagonista, distinguiendo roles y caracteres. A la vez, se funda la primera trama de las tres que cruzan el capítulo: "La Rebelde", protagonizada por Claudia.

En la segunda escena, ya con el antecedente de su fanatismo por el fútbol, arranca la segunda trama, protagonizada por Félix: “El Penal”. El menor de Los Herrera se luce jugando en el colegio, pese a los problemas que le dan sus viejas zapatillas. En la tercera escena arranca la tercera trama: "La Crisis". Es la trama central del capítulo, que comienza con un conflicto ajeno en apariencia: mientras trabaja en la cocina, Ana intenta averiguar con su hija si su marido le compró un regalo por sus 20 años de matrimonio. El protagonista de esta trama es Juan, que en la escena siguiente, en medio de su trabajo en una fábrica textil, se muestra reacio con su amigo y colega Exequiel a la alternativa de comprar con crédito un televisor a color como regalo de aniversario. Así concluye el planteamiento de los personajes principales y las tres historias que conforman el capítulo, que pronto comienzan a intensificarse.

A Félix se le terminan de romper sus zapatillas, lo que amenaza con impedirle jugar la final del campeonato de su colegio. Mientras su madre trata de arreglarlas, el niño fracasa en su intento para que le compren otras porque "no hay plata". Camino a su casa, Juan pasa al almacén de su barrio, atendido por Petita y don Genaro, un ferviente partidario de Pinochet que celebra el anuncio del general de que el peso no se devaluará respecto al dólar. Siguiendo la Tesis del Cuento de Piglia (2014), con este comentario se funda "la historia oculta" que contiene la trama de Juan, bien cubierta por "la historia evidente" del padre de familia admirando el nuevo televisor a color del almacenero y dándole vueltas a la idea de comprar uno para Ana.

Cae la noche y el noticiero gatilla un nuevo conflicto en la trama "La Rebelde": Imágenes de la
Guerra de Las Malvinas con la derrota consumada de los soldados argentinos, provocan un altercado entre Claudia y Martín, porque él está convencido de que los soldados chilenos habrían derrotado a los trasandinos si la guerra hubiera sido entre ambos países. Claudia cuestiona una vez más y con mayor fuerza a los militares chilenos, a diferencia de Martín, que aspira a ser piloto de la Fuerza Aérea. Los hermanos desoyen a su padre, que intenta calmarlos. Félix termina sin querer con la discusión cuando la televisión muestra una nueva nota de la selección de fútbol sobre hinchas que han ido al aeropuerto a despedir a los futbolistas. Juan reconviene al pasar a sus hijos mayores para que dejen de pelear por esos temas, lo que permite conocer más sobre la historia pasada de Los Herrera, sus respectivas creencias y las relaciones entre sus miembros. Lo anterior ocurre en función del conflicto presente, es decir, de manera activa en términos dramáticos, haciendo progresar las tramas que se relatan. Al mismo tiempo se entraman o entrecruzan dos de las tres historias que se narran, "La Rebelde" y “El Penal”, transluciendo una crítica: el uso de fenómenos masivos como el fútbol como tapadera de problemas sociales.

La trama central tiene a continuación su primer punto de giro, cuando Juan asiste a la despedida de uno de sus jefes y un gerente le anuncia que él será promovido a ese cargo. Este hecho cambia el curso de la historia y hace entrar al capítulo en su segundo acto. Juan regresa a su casa algo pasado de copas y lleno de ilusiones, comparte con Ana la buena noticia. Al día siguiente está frente a la vitrina de una tienda de televisores. No termina de quedar claro si el dependiente logra convencerlo sobre las supuestas ventajas de comprar un televisor a crédito. La trama central prosigue en la escena siguiente con Ana y Claudia de nuevo en la cocina, la madre está convencida de que Juan olvidó su aniversario. Acto seguido, se despliega el plan que urde el protagonista con la complicidad de sus hijos y los almaceneros para distraer a Ana y esconder el televisor a colores en la habitación de Félix y Martín. Esa noche, Juan autoriza a sus hijos a ver la televisión y, al abrir la caja del aparato, Félix encuentra zapatillas nuevas para él. El emocionado agradecimiento del niño acrecienta la empatía que se busca construir en el espectador en relación con Juan, dejándonos en claro el objetivo dramático del protagonista: "Mi familia es lo más importante". Frente a la sorpresa de Martín por sus adquisicio- 
nes, Juan le responde con orgullo a su hijo que es fruto de años de trabajo. Una vez más se entraman dos de las historias del capítulo, ahora "El Penal" con "La Crisis", y el capítulo alcanza lo que Field (2001) denomina el punto medio de la historia: un acontecimiento en mitad del segundo acto y del relato que levanta emocionalmente el conflicto y que suele ser un falso triunfo del protagonista. En efecto, esta situación ocurre a la media hora de relato, poco después de la mitad del capítulo, que en total se extiende por 58 minutos.

En la escena siguiente, Juan entra a su habitación y apaga la luz simulando olvidar el aniversario de Ana, con el consiguiente enojo contenido de ella. Las tres tramas prosiguen al día siguiente, primero con Ana despertando de mal humor con el supuesto olvido de su marido, y luego por fin contenta cuando ve el televisor nuevo. Más tarde Félix está a instantes de disputar la final del campeonato, pero su amigo Bruno le comenta que no es recomendable jugar con zapatillas nuevas, por la falta de costumbre. En paralelo, Claudia está orgullosa de su padre por su inminente ascenso laboral. Sin embargo, pronto comienzan los reveses. Primero Félix pierde un penal y su equipo es derrotado. Al salir de clases, su frustración provoca que tire lejos sus zapatillas y un auto las rompa. Mientras le miente a sus padres, sus compañeros de colegio no dejan de molestarlo, por lo que Félix decide hacerse el enfermo para no ir a clases. Juan sabe que su hijo le está ocultando algo, pero es comprensivo con él; de nuevo se cuida la empatía del espectador hacia el protagonista. En eso se retoma la trama central, otra vez con el televisor de Los Herrera y el uso de archivo, con el anuncio oficial de que el peso chileno se devalúa. La crisis económica llega finalmente. Es el segundo quiebre o giro dramático de la historia, que conduce al tercer acto del capítulo.

Pronto Juan se ve angustiado con los rumores de que la fábrica donde trabaja no podrá pagar su crédito en dólares y deberá cerrar. Esta amenaza se entrama con el debut de Chile en el Mundial de España. Las reacciones se centran en Félix y sus compañeros, y en Juan y sus colegas. Después de un penal desperdiciado por Caszely que repercute en el conflicto que vive Félix, el eje del relato regresa a la trama central, con Exequiel comentando a Juan que les llueve sobre mojado con el casi seguro cierre de la fábrica.
La familia come y mira el televisor: Caszely se deshace en explicaciones. Martín insulta al jugador, pero Juan le exige respeto a su hijo, una vez más se cuida la empatía hacia el protagonista. A renglón seguido el noticiero informa sobre la crisis que afecta a la empresa donde trabaja el padre de familia. Una vez más se recurre al televisor, ahora para construir el clímax de las dos tramas principales del capítulo: Juan pide que apaguen el televisor. Ana lo impide, quiere saber si cerrarán la fábrica. Claudia critica a la dictadura: "Son los milicos (militares) mamá, tienen la media escoba (desastre) con la economía". Ana replica que su hija no sabe cómo eran las cosas antes, "ahí sí que estaba la escoba", sostiene aludiendo al gobierno de Allende. Juan interviene, demanda que no se hable de política. Claudia insiste afirmando que se refiere a la crisis económica y Ana, temerosa, le pide a su marido que devuelvan el televisor. Juan intenta calmar a su familia, con Martín suplicando a su padre conservar el televisor y Claudia criticando a su hermano por egoísta. La discusión entre ambos vuelve a subir de tono y Juan se ve obligado a golpear la mesa y gritarle a sus hijos que no hablen de política ni dinero. Así concluye, por este capítulo, la trama “La Rebelde". Como consecuencia del enojo de Juan, Félix se va llorando a su habitación mientras Ana reprueba la reacción de su marido, que se levanta para consolar a su hijo. Aquí ocurre el clímax de "El Penal" y el desenlace de "La Crisis": Félix le confiesa a su padre que su equipo perdió por su culpa y todos lo molestan. Juan ahora entiende lo que le pasaba a su hijo e intenta animarlo. Sin embargo, nota que algo más lo angustia, pero Félix tiene miedo de decírselo "ahora que no tienes plata". El padre conserva el temple y logra que el niño le confiese que rompió sus zapatillas nuevas. Juan lo abraza comprensivo, le pide que no se preocupe. "Ése es un problema chiquitito", afirma casi vaticinando las grandes dificultades que le esperan. La escena siguiente es la última del piloto y el desenlace de la trama de Félix, con Juan enseñándole a su hijo a patear penales y logrando recuperar la alegría del niño.

\subsection{Recapitulación del piloto}

El primer capítulo de Los 80 deja abiertas dos de sus tres tramas, "La Crisis" y "La Rebelde". Ambos relatos invitan a la audiencia a especular qué sucederá con Juan y su familia si él pierde su trabajo, 
y con Claudia si se involucra más en política. Las expectativas y predicciones del espectador sobre el relato de una serie tienen directa relación con los acontecimientos dramáticos que plantea el primer capítulo. Que Juan sea el protagonista, su familia los personajes principales, y sus amigos y vecinos los personajes secundarios, son parte de esas definiciones, además posibles de suponer que se mantendrán en el transcurso de la serie. Se sientan así las bases para que el espectador reconozca los recursos narrativos esenciales del formato seriado y en función de ellos experimente el continuismo novedoso que cada episodio propone.

Profundizando en las proyecciones dramáticas que se definen en el primer capítulo de Los 80 , también se encuentran las aspiraciones de Martín por ser piloto de la Fuerza Aérea y cómo pueden afectar la ya tensa relación que mantiene con su hermana, contraria al mundo militar. Por su lado, Claudia aspira a estudiar medicina y se advierte que no está conforme con su pareja. En cuanto a Ana, se vislumbra que el destino laboral de su marido será determinante en su respectivo desarrollo dramático. En el caso de Félix, la trama que protagoniza en el piloto tiene cierre narrativo, con lo que es posible vislumbrar que su mayor rol dentro de la serie es tener una "nueva aventura" en cada capítulo, con su amigo Bruno como consorte. En relación con los personajes secundarios, se funda que $\mathrm{Pe}$ tita y Genaro son agentes constantes de alivio cómico, contrapesando las historias de Los Herrera. Por el lado de Exequiel se advierte que tiene una postura política contraria al régimen que le puede traer dificultades y que, como Juan, depende del destino de la fábrica.

Para comprender de manera concreta cómo una serie narra las proyecciones dramáticas que establece en su primer capítulo, se analiza el clímax del capítulo 10 de Los 80, "Cualquier cosa, menos mentir", último episodio de la primera temporada.

Los Herrera se encuentran en el comedor, silenciosos. Claudia ha sido recién excarcelada, luego de haber sido detenida por protestar contra la dictadura. Una vez más discute con Martín, que a estas alturas es cadete de la Escuela de Aviación. Los hermanos se acusan de comunista y pinochetista, obligando a Juan a intervenir: "En esta casa hay personas". Acto seguido le revela a su hija que con Ana tuvieron que pedir un crédito para que pudiera estudiar medicina y le exige que busque trabajo si va a la universidad a meterse en política. Claudia quiere irse a su habitación, pero su padre golpea la mesa y la obliga a que lo escuche. La discusión se intensifica, Juan termina golpeando a Martín y Ana decide llevarse a Félix, pero el niño no quiere. Juan les pide a ambos que se queden y que todos lo escuchen bien:

Cuando queda la escoba, la gente como nosotros es la que paga el pato llas consecuencias)... Los generales y los políticos nunca pierden... 0 se quedan con el poder o son los primeros en salir cascando (arrancando)... Y la gente como nosotros es la que se queda... La que tiene que seguir trabajando y pelando el ajo para poder seguir viviendo... Así son las cosas y siempre van a ser así.

El escenario de la acción, el comedor familiar, es el mismo del clímax del capítulo uno. Existe un juego de espejos, pues en el piloto Claudia y Martín también se pelean en ese lugar, así como Juan golpea la mesa. También en ambos momentos, la familia enfrenta posiciones sobre "la escoba" en el país. En el piloto, Juan pudo haber intervenido con la postura que expresa en el capítulo 10 , sin embargo, decide que no es el momento. Se quiere decir con esto que la construcción dramática de una serie permite la posibilidad de entregar explícitamente la tesis, el punto de vista o el mensaje autoral de la historia desde el primer capítulo, si hablamos de un relato que desde su origen tiene pensado lo que quiere decir sobre el tema central que aborda. Si el primer capítulo es el momento adecuado para manifestar la tesis de la historia, es un tema discutible que depende de diversas consideraciones, por ejemplo, el género de la serie. En series dramáticas como Los 80 , el punto de vista autoral que encierra la historia y su protagonista suele no ser explícito hasta el clímax del capítulo final. Ahora bien, los realizadores de una serie con frecuencia desconocen, como en el caso de LoS 80 , si producirán un nuevo ciclo de capítulos. Por lo mismo existe la opción de que la postura autoral se exprese en el transcurso de la primera temporada, más allá de que la tesis e interpretación última de una serie se pueda realizar luego de la emisión de su último capítulo.

En el caso particular del clímax del piloto de Los 80 , las circunstancias dramáticas no parecen apropia- 
das para hacer patente el sentir de Juan/la tesis de la historia; recién comienza el viaje dramático del personaje principal, por lo que la identificación y empatía con el personaje están en construcción. Si Juan hubiera expresado por completo su postura en el capítulo uno, la tesis de la historia no habría alcanzado la misma potencia dramática ni persuasiva que en el clímax de la primera temporada, pues en el piloto estamos recién conociendo al protagonista y nuestro interés por él está en veremos. Se trata, finalmente, de cómo una serie es capaz de elaborar la mejor circunstancia narrativa para expresar su sentido o su postura con la mayor fuerza y efectividad.

En el primer capítulo es más relevante dejar en claro el objetivo del protagonista: Juan quiere lo mejor posible para su familia y mantenerla unida, y eso en concreto es tener un trabajo que les permita estabilidad, lo cual en el piloto queda en entredicho. En el clímax de la primera temporada es posible comprobar que el objetivo de Juan se ha mantenido inalterable, al tiempo que el personaje evoluciona a partir de todo lo que experimenta con la crisis social. El protagonista muestra un arco dramático o de transformación que se hace patente en el clímax del capítulo 10, respondiendo así a una promesa implícita del drama seriado, consistente en que el espectador pueda profundizar en una nueva dimensión o capa del personaje principal ly eventualmente de otros personajes) al término de cada temporada (Venis, 2013).

Otras situaciones espejo entre el piloto y el capítulo final de la primera temporada de Los 80 es que Juan pide nuevamente un crédito, esta vez para la universidad de su hija. También que, a diferencia del capítulo uno, Félix ya no llora con el enojo de su padre ni quiere salir del comedor. Ana tampoco reprocha el enojo de su marido, al contrario, le sonríe emocionada, siempre de su lado. Sería interesante estudiar hasta qué punto los espectadores son conscientes de estos cruces, que integran un nivel más inadvertido y profundo de continuismo novedoso si los comparamos con aspectos más patentes dentro del relato de una serie, como dinámicas entre personajes, escenarios, música y diseño sonoro, así como analizar de qué manera influyen en el desarrollo del interés y emoción por ver una serie, junto con nuestra disposición a volver a verla en el transcurso del tiempo.

\section{Conclusiones}

El interés y la emoción por una serie dependen del despliegue narrativo en el primer capítulo de diversos recursos dramáticos, fundamentalmente, el mundo narrativo, los personajes, los conflictos y las proyecciones dramáticas, a los que se debe volver en cada nuevo capítulo de la serie en función de lo que Goldberg y Rabkin (2003) denominan continuismo novedoso. Esta recurrencia a lo que se funda en el piloto determina de manera relevante el goce y la fidelización de la audiencia. Los espectadores esperan reconocer lo que se narra en la serie y al mismo tiempo experimentar algo nuevo, una progresión en la historia y en los personajes que despierten emociones como empatía, identificación, humor, intriga o revelación de puntos de vista. Por ejemplo, la posición que Juan Herrera expresa en el clímax de la primera temporada de Los 80 , que se demuestra integrada en nuestra cultura.

Atendiendo que el capítulo uno de una serie exhibe el detonante del relato y encierra su posible clímax, en el caso de Los 80, el detonante es la crisis social, el desarrollo del conflicto es cómo esta crisis amenaza el objetivo de Juan de sacar adelante a su familia y mantenerla unida, y el clímax es el resultado de esta lucha. El piloto implica entonces establecer un detonante al servicio del despliegue narrativo de todos los capítulos siguientes hasta el clímax del capítulo final, que puede ocurrir al cierre de la primera temporada o en una temporada posterior. Esto determina que el relato seriado sea abierto, o bien con clausura flexible, como el clímax de la primera temporada de Los 80 , que dio paso a nuevos ciclos de la producción en un comienzo no contemplados.

Para extender la clausura del relato seriado, el piloto debe establecer personajes y conflictos con potencial de progresión dramática en cada nuevo capítulo, los que por sí solos y en conjunto sostengan el interés del espectador por el clímax último de la historia. Un continuismo novedoso efectivo significa lograr un equilibrio entre los recursos dramáticos clásicos y nuevos a los que el guion apela en cada capítulo, a riesgo de perder espectadores por abusar de la reiteración o extraviar la línea narrativa. Esto redunda en que la biblia de una serie es flexible y está al servicio del guion, pues permite la inclusión de nuevos recursos narrativos 
que, expresados o no en el relato, buscan mantener vivo el interés y el goce del espectador. El tema es hasta qué punto innovar. Si en nuevos capítulos el autor altera en exceso los códigos del piloto, la historia se puede volver irreconocible para la audiencia y con eso perderla. Entonces, a la hora de intervenir el relato de una serie en busca de extender su longevidad, el autor tiene presente retomar lo que la hace identificable para seguir obteniendo una historia basada en el continuismo novedoso. Es decir, intenta sorprender y emocionar siendo fiel y coherente con el origen de la serie.

En suma, un resultado satisfactorio de la relación que se establece entre el autor y el receptor de una serie depende de diversos requisitos que se le exigen a este tipo de relato, como desarrollarse en un mundo dramático atractivo, empatizar con los personajes, conflictos que concilien emoción y coherencia, generar expectativas con la progresión de la narración en cada episodio, y exponer tesis, mensajes o puntos de vista sobre los temas que se tratan en los momentos dramáticos apropiados. Es así como desde el primer capítulo el relato seriado establece los cimientos necesarios para su expansión narrativa, determinando hasta qué punto los espectadores, de manera consciente e inconsciente, internalizan y expresan los significados de una serie en distintas circunstancias de sus vidas.

\section{Referencias}

Aumont, J. \& Marie, M. (1990). Análisis del film. Barcelona: Paidós.

Antezana, L. (2015) Las imágenes de la discordia. La dictadura chilena en producciones televisivas de ficción. Buenos Aires: CLACSO.

Antezana, L. \& Mateos-Pérez, J. (2017). Construcción de memoria: la dictadura a través de la ficción televisiva en Chile (2011). Historia Crítica, 66, 109-128.

Balló, J. \& Pérez, X. (2005). Yo ya he estado aquí: Ficciones de la repetición. Barcelona: Anagrama.

Cascajosa, C. (2007). La caja lista: Televisión norteamericana de culto (Kaplan). Barcelona: Laertes.

Castillo, A. M., Simelio, N. \& Ruiz, M. J. (2010). La reconstrucción del pasado reciente a través de la narrativa televisiva. Estudio comparativo de los casos de Chile y España. Comunicación, 1(10), 666-681.

Cuevas, R. (Guionista) \& Quercia, B. (Director). (2008). Un penal a colores [Capítulo de serie de televisión]. En Wood, A. (Productores), Los 80. Santiago: Canal 13.

Cuevas, R. (Guionista) \& Quercia, B. (Director). (2008). Cualquier cosa, menos mentir [Capítulo de serie de televisión]. En Wood, A. (Productores), Los 80. Santiago: Canal 13.

Douglas, P. (2011). Cómo escribir una serie dramática de televisión. Barcelona: Alba.

Field, S. (2001). El manual del guionista: Ejercicios e instrucciones para escribir un buen guion paso a paso. Madrid: Plot.

Fotech. (2020). ¡En alza!: Retransmisión de "Los 80" llega a la $4^{\circ}$ temporada con su rating más alto. Recuperado de https://www.fotech.cl/en-alza-retransmision-de-los-80-llegaa-la-40-temporada-con-su-rating-mas-alto/2020/01/30/

Genette, G. (1989). Palimpsestos: La literatura en segundo grado. Madrid: Taurus. 
Ginzburg, C. (1994). "Indicios. Raíces de un paradigma de inferencias indiciales”. En Ginzburg, C. Mitos, emblemas, indicios. Morfología e Historia. Barcelona: Gedisa, pp. 138-175.

Goldberg, L. \& Rabkin, W. (2003). Successful Television Writing (Wiley Books for Writers). New Jersey: John Wiley \& Sons.

Kantar Ibope Media. (s/f). Ranking de programas de TV. Recuperado de: http://www.kantaribopemedia.cl/

McKee, R. (2002). El guion: Sustancia, estructura, estilo y principios de la escritura de guiones. Barcelona: Alba.

Mateos-Pérez, J. \& Ochoa, G. (2016). Contenido y representación de género en tres series de televisión chilenas de ficción (2008-2014). Cuadernos.info, (39), 55-66.

Mateos-Pérez, J. \& Ochoa, G. (2019). Chile en las series de televisión. Santiago: RIL Editores.

Pérez, X. \& Garin, M. (2013). La narrativa artúrica como modelo para la escritura de series televisivas: Perspectivas históricas y formales. Historia y Comunicación Social, 18, 587-599.

Piglia, R. (2014). Formas breves, Barcelona: Anagrama.

Schlotterbeck, M. (2014). Actos televisados: El Chile de la dictadura visto por el Chile del bicentenario. Contracorriente: Revista de Historia Social y literatura en América Latina, 12(1), 136-157.

Toledano, G. \& Verde, N. (2007). Cómo crear una serie de televisión. Madrid: T\&B Editores.

Venis, L. (Ed.) (2013). Inside the room. Writing Television with the Pros at UCLA Extension Writers Program. New York: Penguin Group.

\section{- Sobre los autores:}

Pablo Unda Henríquez es Periodista, Pontificia Universidad Católica de Chile. Máster en Dirección de Empresa Audiovisual y Doctorando en Investigación en Medios de Comunicación, Universidad Carlos III de Madrid. Diplomado en Desarrollo de Cine y TV, Universidad de California UCLA. Investiga temáticas de producción, narración y memoria audiovisual.

Paz Crisóstomo Flores es Periodista, Pontificia Universidad Católica de Chile. Magíster en Comunicación Política Universidad de Chile. Doctoranda en Investigación en Medios de Comunicación Universidad Carlos III de Madrid. Investiga temáticas de narración audiovisual, calidad periodística, tratamiento informativo y televisión.

\section{- ¿Cómo citar?}

Unda, P. \& Crisóstomo, P. (2020). Análisis narrativo y creación de series dramáticas: la primera temporada de la serie Los 80. Comunicación y Medios, (41), 95-105, doi: 10.5354/0719-1529.2020.56678 